\title{
Congenital primary aphakia
}

INSERM

\section{Source}

INSERM. (1999). Orphanet: an online rare disease and orphan drug data base. Congenital primary aphakia. ORPHA:83461

Congenital primary aphakia (CPA) is characterised by an absence of the lens. The prevalence is unknown. CPA can be associated with variable secondary ocular defects (including aplasia/dysplasia of the anterior segment of the eye, microphthalmia, and in some cases absence of the iris, retinal dysplasia, or sclerocornea). CPA results from early developmental arrest, around the 4th-5th week of embryogenesis, which prevents the formation of any lens structure. Mutations in the FOXE3 gene were identified in three affected siblings born to consanguineous parents. 